\title{
Genetic diversity and population structure of Rheum tanguticum (Dahuang) in China
}

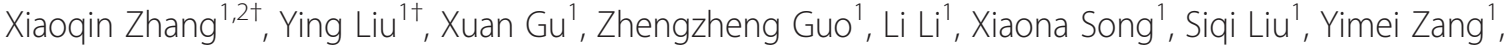 \\ Yanpeng $\mathrm{Li}^{1}$, Chunsheng $\mathrm{Liu}^{{ }^{*}}$ and Shengli Wei ${ }^{*}$
}

\begin{abstract}
Background: Wild Rheum tanguticum (Dahuang in Chinese) has becoming endangered in China. This study aims to examine the genetic structure and genetic diversity of $R$. tanguticum within species, and the genetic differentiation within and among populations in China.

Methods: The variability and structure of 19 populations of $R$. tanguticum were investigated by their chloroplast DNA matK sequences. The genetic diversity index was calculated by Dnasp, PERMUT, and Arlequin 3.0 software, and a neighbor-joining ( $\mathrm{NJ}$ )-tree was constructed by MEGA 5.0 software.

Results: Fifteen haplotypes were obtained based on the matK sequence analysis. The mean genetic diversity within species was 0.894 , and the genetic variability among populations (67.6\%) was relatively higher than that within populations (13.88\%) according to the AMOVA and PERMUT analyses. The NJ-tree and a pairwise difference analysis indicated geographical isolation of $R$. tanguticum. The gene flow among populations was 0.05 , indicating a genetic drift among some populations, which was also confirmed by the NJ-tree and haplotype distributions. Furthermore, a mismatch distribution analysis revealed the molecular evolution of $R$. tanguticum.
\end{abstract}

Conclusion: Genetic diversity among and within populations of $R$. tanguticum in China was demonstrated.

\section{Background}

Rheum tanguticum Maxim. ex Balf belongs to the family Polygonaceae, and grows mainly in high-altitude areas in the southwest and northwest of China, such as Sichuan, Gansu, and Qinghai provinces [1,2]. The rhizomes and roots of $R$. tanguticum (Dahuang in Chinese) are used in Chinese medicine for unloading the tapping product, clearing re (heat), purging huo (fire), removing pathogenic huo from the xue (blood), stimulating menstrual flow, and promoting diuresis and detoxification [3-7]. The huge demand for $R$. tanguticum has caused excessive consumption in China [8-11]. The reproductive rate of $R$. tanguticum is low and environment-dependent, and the wild resources of $R$. tanguticum are becoming endangered [12].

Genetic diversity involves organism complexity [13], ecosystem recovery [14], and species sensitivity to environmental changes [15]. A lack of diversity reflected

\footnotetext{
*Correspondence: max_liucs@263.net; WSL7491@126.com

${ }^{\dagger}$ Equal contributors

${ }^{1}$ School of Chinese Pharmacy, Beijing University of Chinese Medicine, No. 6 Wangjing Zhonghuan South Street, Chaoyang District, Beijing 100102, China Full list of author information is available at the end of the article
}

evidence for potential population endangerment [16,17]. Various molecular markers were used to investigate the genetic diversity of $R$. tanguticum. Chen et al. [18] discovered a relatively high genetic diversity at the species level and a low genetic diversity within populations of $R$. tanguticum by evaluating an SSR marker. These findings were in accordance with those of Wang et al. [19] based on an ISSR marker. However, Hu et al. [20] demonstrated a similar result at the species level, but an opposite result within and among populations of $R$. tanguticum using an ISSR marker. These studies of $R$. tanguticum genetic diversity involved limited materials, and their results were contradictory. Therefore, large samples and new molecular markers were required to reveal the real state of $R$. tanguticum genetic diversity.

The mat $\mathrm{K}$ gene (1500 bp) is a molecular marker for plant molecular systematics and evolution, and is located within the intron of the chloroplast gene $\operatorname{trnK}$ on the large single-copy section adjacent to the inverted repeat [21]. Among various other molecular markers, the mat $\mathrm{K}$ gene sequence avoided any interference of heterozygosity 


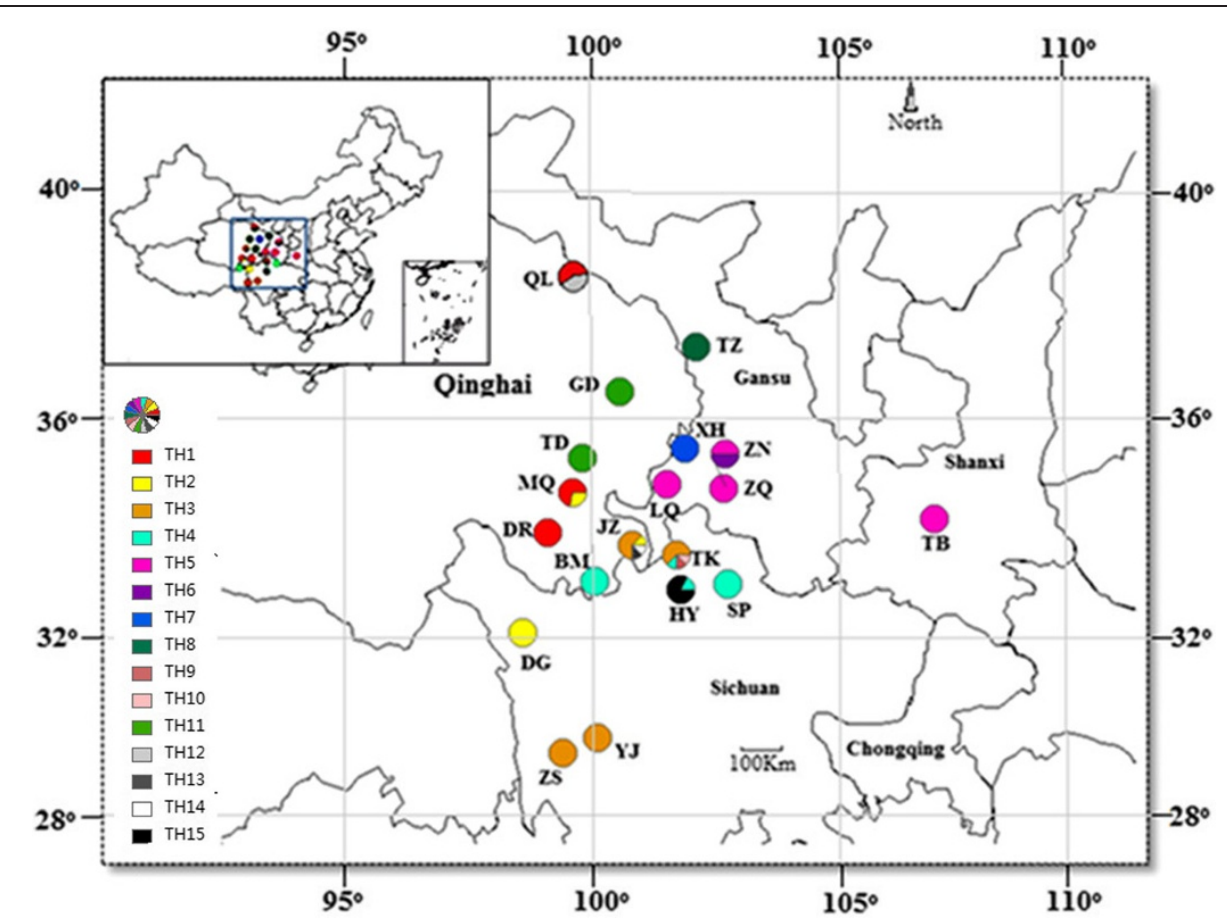

Figure 1 Geographic distributions of the 19 populations and 15 haplotypes. The pie chart shows the proportions of haplotypes in each population. The haplotype information was listed in Table 2.

Table 1 The 19 populations of $R$. tanguticum and thei haplotypes (TH1-TH15) based on the matK gene sequences

\begin{tabular}{|c|c|c|c|c|c|c|}
\hline Code & Locality & Altitude(m) & Number of samples & Haplotypes & $\mathrm{Hd}$ & $\mathrm{Pi}$ \\
\hline BM & Banma, Qinghai & 3694 & 20 & $\mathrm{TH} 4(20)$ & 0 & 0 \\
\hline DR & Dari,Qinghai & 3981 & 21 & $\mathrm{TH} 1(21)$ & 0 & 0 \\
\hline MQ & Maqin,Qinghai & 3746 & 21 & $\mathrm{TH} 1(15), \mathrm{TH} 2(6)$ & 0.476 & 0.00063 \\
\hline GD & Guide,Qinghai & 3728 & 12 & $\mathrm{TH} 11(12)$ & 0 & 0 \\
\hline QL & Qilian,Qinghai & 2981 & 18 & $\mathrm{TH} 1(10), \mathrm{TH} 12(8)$ & 0.523 & 0.00276 \\
\hline$J Z$ & Jiuzhi,Qinghai & 3649 & 8 & $\mathrm{TH} 2(1), \mathrm{TH} 3(5), \mathrm{TH} 13(1), \mathrm{TH} 14(1)$ & 0.643 & 0.00144 \\
\hline TD & Tongde,Qinghai & 3728 & 20 & $\mathrm{TH} 11(20)$ & 0 & 0 \\
\hline DG & Dege,Sichuan & 3934 & 20 & $\mathrm{TH} 2(20)$ & 0 & 0 \\
\hline HY & Hongyuan,Sichuan & 3492 & 12 & $\mathrm{TH} 4(2), \mathrm{TH} 15(10)$ & 0.333 & 0.00022 \\
\hline SP & Songpan,Sichuan & 3282 & 10 & $\mathrm{TH} 4(10)$ & 0 & 0 \\
\hline TK & Tangke,Sichuan & 3447 & 8 & $\mathrm{TH} 3(5), \mathrm{TH} 4(1), \mathrm{TH} 9(1), \mathrm{TH} 10(1)$ & 0.643 & 0.00115 \\
\hline ZS & Zhuosang,Sichuan & 2700 & 10 & $\mathrm{TH} 3(10)$ & 0 & 0 \\
\hline YJ & Yajing,Sichuan & 4122 & 21 & $\mathrm{TH} 3(21)$ & 0 & 0 \\
\hline $\mathrm{XH}$ & Xiahe,Gansu & 3360 & 20 & $\mathrm{TH}(20)$ & 0 & 0 \\
\hline TB & Taibai,Shanxi & 2833 & 21 & $\mathrm{TH}(21)$ & 0 & 0 \\
\hline TZ & Tianzhu,Gansu & 3098 & 22 & $\mathrm{TH}(22)$ & 0 & 0 \\
\hline ZN & Zhuoni,Gansu & 3558 & 8 & $\mathrm{TH} 5(4), \mathrm{TH} 6(4)$ & 0.667 & 0.0022 \\
\hline ZQ & Zhouqu,Gansu & 3000 & 10 & TH5(10) & 0 & 0 \\
\hline LQ & Luqu,Gansu & 3233 & 12 & $\mathrm{TH} 5(12)$ & 0 & 0 \\
\hline
\end{tabular}

Hd: haplotype diversity; Pi: nucleotide diversity. The haplotype information is listed in Table 2. 
Table 2 Variable sites in the matK gene sequences of the $15 R$. tanguticum haplotypes

\begin{tabular}{|c|c|c|c|c|c|c|c|c|c|c|c|c|c|c|c|c|c|c|c|c|c|c|}
\hline \multicolumn{23}{|l|}{ SNP } \\
\hline Haplotype & 30 & 106 & 367 & 443 & 619 & 743 & 764 & 769 & 793 & 803 & 859 & 883 & 937 & 1022 & 1055 & 1106 & 1108 & 1117 & 1156 & 1267 & 1410 & GenBank No. \\
\hline TH1 & A & G & $C$ & $\mathrm{~T}$ & A & C & A & $\mathrm{T}$ & G & $\mathrm{T}$ & C & C & C & C & C & $T$ & C & G & $C$ & A & $\mathrm{T}$ & KF880247 \\
\hline TH2 & * & * & * & * & * & * & * & * & * & * & A & * & * & * & * & * & * & * & * & * & * & KF880035 \\
\hline TH3 & * & * & * & A & * & A & $*$ & $*$ & * & * & * & * & * & * & * & * & * & * & * & * & * & KF880114 \\
\hline $\mathrm{TH} 4$ & * & * & * & * & * & * & T & * & * & * & * & * & * & * & * & * & * & * & * & * & * & KF880006 \\
\hline TH5 & * & * & $*$ & A & C & A & * & G & * & * & $*$ & * & * & $*$ & * & * & * & * & * & * & $*$ & KF880160 \\
\hline TH6 & * & * & $*$ & * & * & * & * & * & A & * & $*$ & * & * & $*$ & * & * & * & * & * & * & * & KF880104 \\
\hline TH7 & * & * & * & A & * & A & $*$ & G & * & $*$ & A & * & $\mathrm{T}$ & * & * & * & T & * & * & * & G & KF880127 \\
\hline TH8 & * & A & T & A & * & A & * & G & * & A & $*$ & * & T & $\#$ & * & * & $\mathrm{T}$ & A & * & * & G & KF879968 \\
\hline TH9 & * & * & * & A & C & A & * & G & * & * & * & * & * & * & * & * & * & * & * & G & * & KF879969 \\
\hline TH10 & * & * & * & A & * & A & * & $*$ & * & * & * & * & * & * & * & * & * & * & T & * & * & KF879972 \\
\hline TH11 & * & * & T & A & * & A & * & G & * & A & * & * & T & * & * & * & $\mathrm{T}$ & * & * & * & G & KF879978 \\
\hline TH12 & G & * & T & A & * & A & * & G & * & A & * & * & $\mathrm{T}$ & * & * & T & * & * & * & * & G & KF880023 \\
\hline TH13 & * & * & * & A & * & * & T & * & * & * & * & * & * & * & * & * & * & * & * & * & * & KF880032 \\
\hline TH14 & * & * & * & A & $C$ & $A$ & * & G & * & $*$ & $*$ & A & * & $*$ & T & * & * & * & * & * & * & KF880033 \\
\hline TH15 & * & * & * & * & * & $*$ & * & * & * & $*$ & * & * & * & * & * & * & * & * & * & * & * & KF880051 \\
\hline
\end{tabular}

\#: TAAACC. An asterisk indicates that the character states are the same as TH1. 
and its evolutionary rate was relatively fast $[22,23]$. Therefore, in recent years, the mat $\mathrm{K}$ gene has been employed as an important and powerful tool for examining intergenus and intragenus genetic diversity because of its high substitution rate $[24,25]$.

This study aims to examine the genetic structure and genetic diversity of $R$. tanguticum within species, and the genetic differentiation within and among populations in China. The genetic diversity of $R$. tanguticum at the species level and within and among populations was investigated using the matK gene sequences, and the population structure of $R$. tanguticum was clarified.

\section{Methods}

\section{Plant materials}

A total of $276 R$. tanguticum individuals were collected from 19 populations in Sichuan, Gansu, and Qinghai provinces of China (Figure 1). Each population was composed of 10-20 individuals spaced $50 \mathrm{~m}$ apart from one another. Tender leaves of each sample were stored in ziplock bags with silica gel. The latitude, longitude, and altitude of each collection site were recorded by an Etrex GIS unit (Garmin, Taiwan). The sample information is listed in Table 1.

\section{DNA extraction, PCR amplification, and sequencing}

Total DNA was extracted from the silica gel-dried leaves using the CTAB method [26]. The matK region was amplified with three pairs of primers. The first primer pair was trnK1895F (5'-GACATCCCATTAGTAAGCC-3') and $\operatorname{trnK2R}$ (5'-AACTAGTCGGATGGAGTAG-3'), the second primer pair was matkK592F (5'-TCCTACCGTGT GTGAATGCG-3') and matK8R (5'-AAAGTTCTAGCA CAAGAAAGTCGA-3'), and the third primer pair was Pt-trnK692F (5'-GACTGTATCGCACTATGTATC-3') and trnK1544R (5'-GGATAACCCCAGAATGCTTAG-3'). All primers were synthesized by Shanghai Shenggong Company (China). Each PCR amplification was performed in a $50-\mu \mathrm{L}$ reaction mixture by a Cycler ${ }^{\mathrm{ru}}$ Thermal Cycler (Bio-Rad, USA) PCR procedure as follows: $94^{\circ} \mathrm{C}$ for $5 \mathrm{~min}$; 35 cycles of $94^{\circ} \mathrm{C}$ for $45 \mathrm{~s}$, annealing at $51^{\circ} \mathrm{C}$ for $1 \mathrm{~min}$, and extension at $72^{\circ} \mathrm{C}$ for $1 \mathrm{~min}$; final extension at $72^{\circ} \mathrm{C}$ for 10 min. A $1 / 10$ volume of each PCR product was examined by electrophoresis in a $1.0 \%(\mathrm{w} / \mathrm{v})$ agarose gel, and the remaining part was sequenced for correction.

\section{Data analysis}

Sequences were aligned by ClustalX [27] and manually adjusted by BioEdit v.7.0.9 [28]. All gaps were treated as missing characters. Dnasp 4.0 estimated the molecular diversity, including the number of segregating sites $(\mathrm{S})$, number of haplotypes (Nh), haplotype diversity $(\mathrm{Hd})$, and nucleotide diversity $(\mathrm{Pi})$ [29]. The Dnasp 4.0 also performed Tajima's test and calculated the mismatch distributions [30]. PERMUT calculated the average gene diversity within populations $(\mathrm{Hs})$, total gene diversity $(\mathrm{Ht})$, and two measures of population differentiation, GST and NST (equivalent coefficient taking into account sequence similarities among haplotypes) [31]. Arlequin 3.0 software performed an analysis of molecular variance (AMOVA) to analyze the pairwise differences among and within populations [32]. The DNA divergences among populations (Fst) were measured, and the significances were tested using 10,000 permutations [33]. Gene flow between pairs of populations was calculated based on the Fst values $(\mathrm{Nm}=(1-\mathrm{Fst}) / 4$ Fst $)$. Statistical Product and Service Solutions (SPSS) calculated the correlation between genetic difference and geographic distance. A molecular phylogenetic tree was constructed by the neighbor-joining (NJ) method in MEGA 5.0, based on 87 samples including all of the haplotypes [34]. Insertions and deletions of base pairs were removed by the bootstrap method with 1000 replicates.

\section{Results}

\section{Haplotypes and their distribution analysis}

Among the 19 populations, a 1518-bp matK sequence was obtained from 18 populations. The only exception was the TZ population from Gansu province, which produced a 1524-bp matK sequence with a 'TAAACC' insertion at the 1022-bp site. A total of 21 segregated sites were found in the matK sequence of $R$. tanguticum, and 15 haplotypes were determined (Table 2). There was only one haplotype in 13 populations, two different haplotypes in four populations, and four different haplotypes in the JZ and TK populations (Figure 1, Table 1). Among the 15 haplotypes, three haplotypes, TH3, TH4, and TH5, were simultaneously detected in four different populations. Two haplotypes, TH1 and TH2, were simultaneously detected in three different populations. TH11 was detected in two populations at the same time. The other nine haplotypes, TH6, TH7, TH8, TH9, TH10,

Table 3 Analysis of molecular variance (AMOVA) results for all haplotypes

\begin{tabular}{|c|c|c|c|c|c|c|}
\hline Source of variation & d.f. & SSD & Variance component & Percentage of variation & F-statistics & $P$ value \\
\hline Among groups & 2 & 96.13 & 0.5026 & 18.52 & $\mathrm{FCT}=0.18523$ & $=0.056$ \\
\hline Among populations & 16 & 264.65 & 1.83423 & 67.6 & $\mathrm{FST}=0.82996$ & $<0.001^{*}$ \\
\hline Within populations & 154 & 57.996 & 0.3766 & 13.88 & $F S C=0.86121$ & $<0.001^{*}$ \\
\hline Total & 172 & 172 & 2.71343 & - & - & - \\
\hline
\end{tabular}

d.f.: degrees of freedom; SSD: sum of squares. *Significance values after 1000 permutations. 
Table 4 Matrix of pairwise differences (Fst) among the 19 populations calculated by analysis of molecular variance (AMOVA)

\begin{tabular}{|c|c|c|c|c|c|c|c|c|c|c|c|c|c|c|c|c|c|c|c|}
\hline & DR & MQ & $\mathrm{QL}$ & DG & $J Z$ & YJ & TK & ZS & SP & $\mathrm{HY}$ & BM & TB & ZN & LQ & ZQ & $\mathrm{XH}$ & TZ & TD & GD \\
\hline DR & 0 & & & & & & & & & & & & & & & & & & \\
\hline MQ & 0.19192 & 0.00000 & & & & & & & & & & & & & & & & & \\
\hline QL & 0.30703 & 0.29714 & 0.00000 & & & & & & & & & & & & & & & & \\
\hline DG & 1.00000 & 0.68627 & 0.52787 & 0.00000 & & & & & & & & & & & & & & & \\
\hline$J Z$ & 0.41905 & 0.28881 & 0.26365 & 0.65143 & 0.00000 & & & & & & & & & & & & & & \\
\hline YJ & 1.00000 & 0.71530 & 0.32458 & 1.00000 & 0.03175 & 0.00000 & & & & & & & & & & & & & \\
\hline TK & 0.46154 & 0.35667 & 0.26264 & 0.74074 & 0.08374 & 0.00000 & 0.00000 & & & & & & & & & & & & \\
\hline ZS & 1.00000 & 0.65087 & 0.27098 & 1.00000 & 0.04007 & 0.00000 & 0.06870 & 0.00000 & & & & & & & & & & & \\
\hline SP & 1.00000 & 0.81274 & 0.56258 & 1.00000 & 0.69817 & 1.00000 & 0.75998 & 1.00000 & 0.00000 & & & & & & & & & & \\
\hline HY & 0.87885 & 0.43460 & 0.40379 & 0.87885 & 0.46032 & 0.93529 & 0.55155 & 0.91501 & 0.85957 & 0.00000 & & & & & & & & & \\
\hline BM & 1.00000 & 0.77716 & 0.52787 & 1.00000 & 0.65143 & 1.00000 & 0.72000 & 1.00000 & 0.00000 & 0.82918 & 0.00000 & & & & & & & & \\
\hline TB & 1.00000 & 0.87597 & 0.46108 & 1.00000 & 0.58503 & 1.00000 & 0.63158 & 1.00000 & 1.00000 & 0.96650 & 1.00000 & 0.00000 & & & & & & & \\
\hline ZN & 0.51515 & 0.31004 & 0.24580 & 0.67347 & 0.11355 & 0.51515 & 0.16579 & 0.39394 & 0.73366 & 0.40043 & 0.67347 & 0.51515 & 0.00000 & & & & & & \\
\hline LQ & 1.00000 & 0.90289 & 0.50836 & 1.00000 & 0.65147 & 1.00000 & 0.69331 & 1.00000 & 1.00000 & 0.97471 & 1.00000 & 0.00000 & 0.61290 & 0.00000 & & & & & \\
\hline ZQ & 1.00000 & 0.80734 & 0.35664 & 1.00000 & 0.43101 & 1.00000 & 0.48803 & 1.00000 & 1.00000 & 0.94340 & 1.00000 & 0.00000 & 0.25000 & 0.00000 & 0.00000 & & & & \\
\hline$X H$ & 1.00000 & 0.92071 & 0.38671 & 1.00000 & 0.77656 & 1.00000 & 0.81081 & 1.00000 & 1.00000 & 0.97740 & 1.00000 & 1.00000 & 0.80247 & 1.00000 & 1.00000 & 0.00000 & & & \\
\hline TZ & 1.00000 & 0.97706 & 0.72091 & 1.00000 & 0.93564 & 1.00000 & 0.94734 & 1.00000 & 1.00000 & 0.99347 & 1.00000 & 1.00000 & 0.95067 & 1.00000 & 1.00000 & 1.00000 & 0.00000 & & \\
\hline TD & 1.00000 & 0.95495 & 0.46208 & 1.00000 & 0.87319 & 1.00000 & 0.89480 & 1.00000 & 1.00000 & 0.98717 & 1.00000 & 1.00000 & 0.89565 & 1.00000 & 1.00000 & 1.00000 & 1.00000 & 0.00000 & \\
\hline GD & 1.00000 & 0.95495 & 0.46208 & 1.00000 & 0.87319 & 1.00000 & 0.89480 & 1.00000 & 1.00000 & 0.98717 & 1.00000 & 1.00000 & 0.89565 & 1.00000 & 1.00000 & 1.00000 & 1.00000 & 0.00000 & 0.00000 \\
\hline
\end{tabular}


TH12, TH13, TH14, and TH15, were only detected in one population.

\section{Genetic diversity analysis}

The genetic diversity of the mat $\mathrm{K}$ sequences was relatively low in the same population, but relatively high in different populations (Table 1, Figure 1). The highest genetic diversity was observed in population $\mathrm{ZN}(\mathrm{Hd}=0.667$, $\mathrm{Pi}=0.0022$ ), while the lowest genetic diversity was observed in 13 populations, e.g., $\mathrm{TH} 4(\mathrm{Hd}=0, \mathrm{Pi}=0)$. The changes in Pi showed a similar trend toward haplotype diversity, and the only difference was that the highest Pi was found in population $\mathrm{QL}(\mathrm{Pi}=0.00276)$, rather than population $\mathrm{ZN}$ $(\mathrm{Pi}=0.0022)$. The $\mathrm{Hd}$ and $\mathrm{Pi}$ values within the species were 0.894 and 0.00308 , respectively, demonstrating a relatively high level of genetic diversity.

\section{Genetic differentiation and genetic difference analysis}

The AMOVA results showed high variability among the populations (Table 3). The genetic differentiation among and within populations was $67.6 \%(\mathrm{FST}=0.82996)$ and $13.88 \%$ ( $F S C=0.86121$ ), respectively. The genetic differentiation was mainly observed among populations. According to the results of the PERMUT analysis, the genetic diversity among populations $(\mathrm{Ht}=0.918)$ was higher than that within populations $(\mathrm{Hs}=0.173)$, which was consistent with the AMOVA results. The value of NST (0.854) was higher than the value of GST (0.812), indicating a differentiation of geographical structure among populations of R. tanguticum.

The genetic differences according to the AMOVA results were listed in Table 4. The pairwise Fst values varied from 0 to 1 , and most of the pairwise Fst values between populations were significant $(P<0.05)$. The SPSS analysis demonstrated a significant positive relationship between genetic difference and geographic distance (Figure 2).

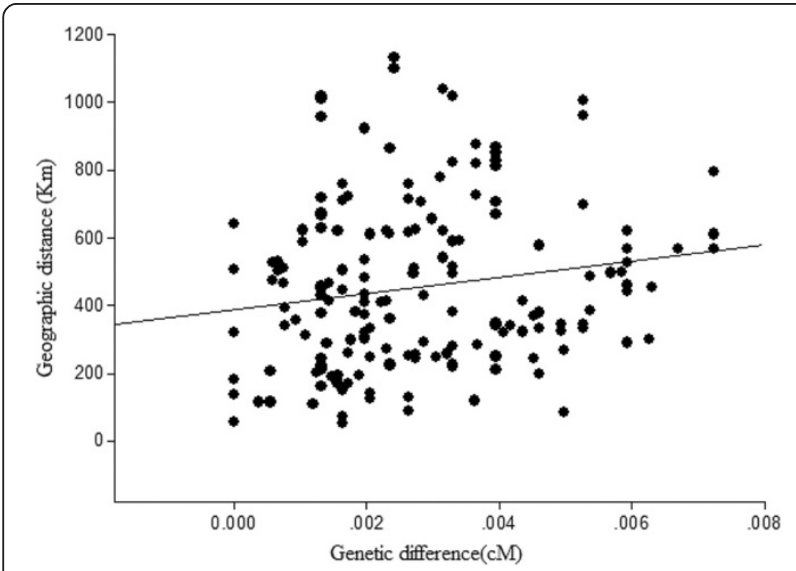

Figure 2 SPSS analysis results for the correlation between genetic difference and geographical distance. $R^{2}=0.028 ; P=0.036$.

\section{Genetic structure analysis}

An NJ-tree was constructed based on the matK gene sequences of $87 R$. tanguticum samples (Figure 3). The 87 samples were clustered together into two groups, one including the LQ and TB populations, and the other including the remaining 17 populations, which were further clustered into three subgroups. In general, samples from the same population were clustered together, such as the samples from populations QL, TZ, TD, and GD. However, several samples from the same population were clustered into different subgroups, for example, JZ-1, JZ-2, JZ-3, JZ-4, JZ-5, JZ-6, JZ-7, and JZ-8 were all collected from population JZ, but were clustered with different populations.

The results of the NJ-tree analysis were consistent with those of the genetic difference analysis between populations. The genetic differences between populations $\mathrm{YJ}$ and $\mathrm{TK}, \mathrm{SP}$ and $\mathrm{BM}, \mathrm{DR}$ and $\mathrm{MQ}, \mathrm{TB}$ and $\mathrm{ZQ}$, and TD and GD were all zero, and these populations were clustered into one subgroup on the NJ-tree. Meanwhile, the genetic differences between populations GD and DR, MQ and TD, and TZ and DG were significant, and they were clustered into different subgroups on the NJ-tree. However, some populations, such as YJ and ZQ, and LQ and YJ, were clustered into the same subgroups on the NJ-tree, but the genetic differences between them were significant $(\mathrm{Fst}=1)$.

\section{Mismatch distribution analysis}

A mismatch distribution analysis based on Dnasp was performed, and multi-peak traces were obtained to explain the gene exchange present among different populations of $R$. tanguticum (Figure 4). Tajima's test (Tajima's $\mathrm{D}=1.09761, P>0.10$ ) demonstrated the presence of gene exchange among $R$. tanguticum populations. The average number of migrants $(\mathrm{Nm})$ between populations calculated by AMOVA and Dnasp was 0.05 for both analyses.

\section{Discussion}

In this study, a relatively high genetic diversity was found in $R$. tanguticum, and the genetic diversity among populations was higher than that within populations. Endangered species often showed a relatively low level of genetic diversity [35-38], which was not consistent with this study. In general, many factors were found to influence genetic diversity, such as environmental, genetic, and human factors [39]. $R$. tanguticum is a herbaceous perennial with a long living history [19] and self-incompatible species [23], and its pollen is widely spread from Gansu Province to the Tibet autonomous region in China, i.e., different environmental and climate conditions, thereby enhancing gene exchange and leading to high genetic diversity [40-43]. 


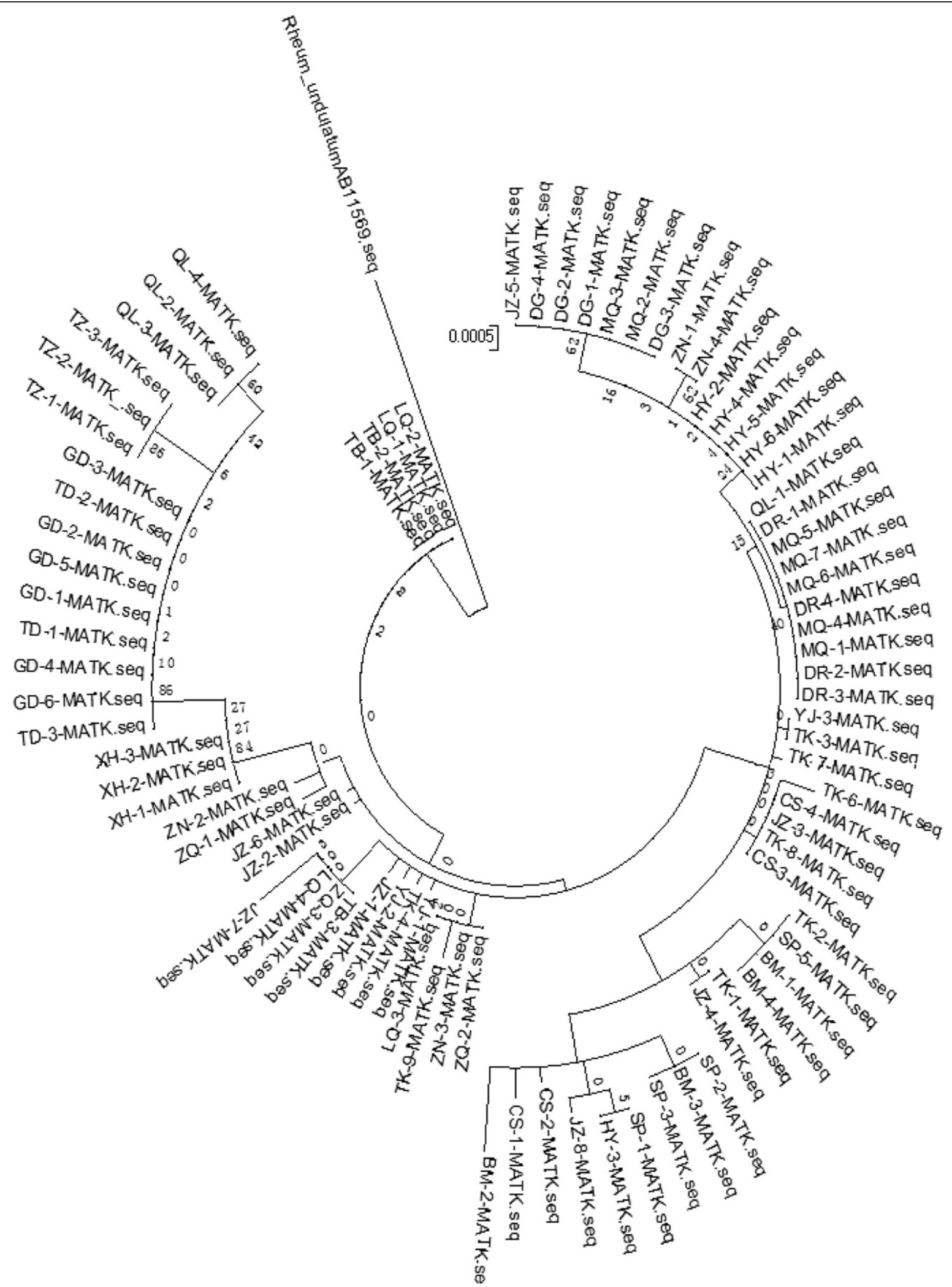

Figure $3 \mathrm{NJ}$-tree constructed based on the matK gene sequences of $\mathbf{8 7}$ R. tanguticum samples. R. undulatum [GenBank: AB11569] was used as the outgroup. 


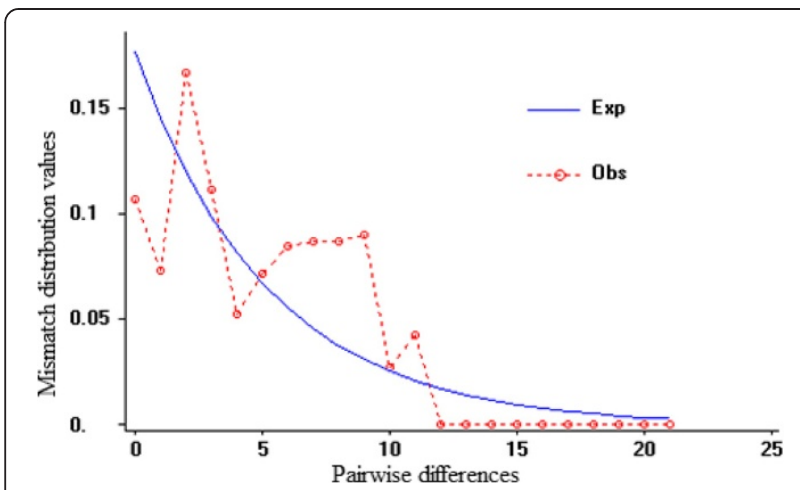

Figure 4 Mismatch distributions based on the matK gene sequences of the individual samples. The straight line represents the expected values and the dotted line represents the observed values.

The distribution of the 15 haplotypes and the SPSS analysis results demonstrated a significant positive relationship between genetic difference and geographic distance. On the NJ-tree, the samples from the same population were clustered together, and the samples from different populations were clustered into different subgroups. Geographic isolation, e.g., by mountains and rivers, was noted among different populations of $R$. tanguticum, and explained why the genetic diversity differed among populations. In this study, the geographic distance between populations JZ and BM was close, but the difference in their haplotypes was significant.

Haplotypes TH1-TH5 were present in different populations at the same time. However, in two populations, JZ and TK, many different haplotypes were simultaneously observed. Although the geographic distances between populations ZS and JZ, DR and QL, and TB and LQ were significant, they had the same genotypes, respectively. On the NJ-tree, some samples from the same population did not cluster into the same subgroup, such as the samples from populations JZ and TK. The genetic differentiation of $R$. tanguticum mainly occurred among different populations. The multi-peak traces and Tajima's test results (Tajima's $\mathrm{D}=1.09761, P>0.10)$ demonstrated that the evolution of $R$. tanguticum was consistent with the neutral theory [44], indicating that it did not experience huge environmental changes and rapid expansion. The adaptive capacity to an environment is decided by the genetic diversity of the species, which is also an important index for its long-term survival [45]. As our samples were all collected from untraversed fields without human interference, the gene exchange phenomenon was the result of early accumulation of genetic diversity.

\section{Conclusion}

Genetic diversity among and within populations of $R$. tanguticum in China was demonstrated.

\section{Abbreviations}

SSR: Simple sequence repeats; ISSR: Inter-simple sequence repeats; GST: Coefficient of gene differentiation; NST: Coefficient of gene differentiation taking into account sequence differences; AMOVA: Analysis molecular variance; SPSS: Statistical Product and Service Solutions; Fst: Genetic differentiation values.

\section{Competing interests}

The authors declare that they have no competing interests.

\section{Authors' contributions}

$\mathrm{CL}$ and $\mathrm{SW}$ conceived and designed the study. $\mathrm{XZ}, \mathrm{YL}, \mathrm{XG}$, and $\mathrm{ZG}$ performed the experiments. $X Z$ and $Y L$ wrote the manuscript. $L L, X S$, and $S L$ analyzed data. YZ and YPL searched and reviewed literature. All authors read and approved the final manuscript.

\section{Acknowledgments}

This work was supported by the National Natural Science Fund (30973880, 31170307). We would like to thank Associate Professors Yuan Zhang and Zhenfang Bai (Beijing University of Chinese Medicine, Beijing, China) for their critical review of the manuscript. We would also like to thank Xiaoli Cheng, Guofu Zhou, Ye Tian, and Yongjie Li for their generous help in this study.

\section{Author details}

${ }^{1}$ School of Chinese Pharmacy, Beijing University of Chinese Medicine, No. 6 Wangjing Zhonghuan South Street, Chaoyang District, Beijing 100102, China. ${ }^{2}$ Lishui Hospital of Chinese Medicine, Zhejiang 323000, China.

Received: 25 January 2014 Accepted: 21 October 2014

Published: 3 November 2014

\section{References}

1. Wu Z, Raven PH, Garden MB: Zhong Guo Zhi Wu Zhi (Flora of China). Beijing: Science Press; 1994.

2. Wang XM, Ren $Y$ : Rheum tanguticum, an endangered medicinal plant endemic to China. J Med Plants Res 2009, 3:1195-1203.

3. Li AR: Flora Reipublicae Popularis Sinicae. Beijing: Science Press; 1998.

4. Wu YH: The floristic characteristics in the region of Bayan Har Mountains. Acta Bot 2004, 6:587-603.

5. Xiao P, He L, Wang L: Ethnopharmacologic study of Chinese Rhubarb. J Ethnopharmacol 1984, 10:275-293.

6. Duke JA: Handbook of Medicinal Herbs. Boca Raton: CRC Press; 2002.

7. China Pharmacopoeia Committee: Pharmacopoeia of the People's Republic of China. Beijing: Chemical Industry Press; 2010.

8. Hamilton AC: Medicinal plants, conservation and livelihoods. Biodivers Conserv 2004, 13:1477-1517.

9. Mentreddy SR: Review-medicinal plant species with potential antidiabetic properties. J Sci Food Agric 2007, 87:743-750.

10. Reddy KN, Reddy CS: First red list of medicinal plants of Andhra Pradesh, India-conservation assessment and management planning. Ethnobot Lealf 2008, 12:103-107.

11. Zhang DY, Chen N, Yang YZ, Zhang Q, Liu JQ: Development of 10 microsatellite loci for Rheum tanguticum (Polygonaceae). Conserv Genet 2008, 9:475-477.

12. Yu H, Xie CX, Song JY, Zhou YQ, Chen SL: TCMGIS-II based prediction of medicinal plant distribution for conservation planning:a case study of Rheum tanguticum. Chin Med 2010, 5:31-40.

13. Lynch M, Conery JS: The origins of genome complexity. Science 2003, 302:1401-1404.

14. Reusch TBH, Ehlers A, Hammerli A, Worm B: Ecosystem recovery after climatic extremes enhanced by genotypic diversity. Natl Acad Sci USA 2005, 102:2826-2831.

15. O'brien SJ: A role for molecular genetics in biological conservation. Proc Natl Acad Sci U S A 1994, 91:5748-5755.

16. Amos W, Balmford A: When does conservation genetics matter? Heredity 2001, 87:257-265.

17. Bazin E, Glémin S, Galtier N: Population size does not influence mitochondrial genetic diversity in animals. Science 2006, 312:570-572.

18. Chen FJ, Wang AL, Chen KM, Wan DS, Liu JQ: Genetic diversity and population structure of the endangered and medically important Rheum 
tanguticum (Polygonaceae) revealed by SSR markers. Bioch Syst Ecol 2009, 37:613-621.

19. Wang $X M$, Yang R, Feng SF, Hou XQ, Zhang YQ, Li Y, Ren Y: Genetic variation in Rheum palmatum and Rheum tanguticum (polygonaceae), two medicinally and endemic species in China using ISSR markers. Plos one 2012, 7:e51667.

20. Hu YP, Wang L, Xie XL, Yang J, Li Y, Zhang HG: Genetic diversity of wild populations of Rheum tanguticum endemic to China as revealed by ISSR analysis. Bioch Syst Ecol 2010, 38:264-274.

21. Hilu $\mathrm{K}$, Liang $\mathrm{H}$ : The matK gene: sequence variation and application in plant systematics. Am J Bot 1997, 6:830-839.

22. Cao H, Sasaki Y, Fushimi H, Komatsu K: Molecular analysis of medicinallyused Chinese and Japanese curcuma based on $18 \mathrm{~s}$ rRNA gene and trnK gene sequences. Biol Pharm Bull 2001, 24:1389-1394.

23. Zhu S, Fushimi H, Cai SQ, Komatsu K: Phylogenetic relationship in the genus panax: inferred from chloroplast trnK gene and nuclear $18 \mathrm{~S}$ rRNA gene sequences. Planta Med 2003, 69:647-653.

24. Yang DY, Hirotoshi F, Cai SQ, Katsuko K: Molecular analysis of Rheum species used as Rhei Rhizoma based on the chloroplast matK gene sequence and its application for identification. Biol Pharm Bull 2004, 3:375-383.

25. Koch M, Haubold B, Mitchell-Olds T: Molecular systematics of the Brassicaceae: evidence from coding plastidic matK and nuclear Chs sequences. Am J Bot 2001, 3:534-544.

26. Rofers SO, Bebdich AJ: Extraction of DNA from plant tissues. Plant Mol Biol 1998, A6:1-10.

27. Thompson JD, Gibson TJ, Plewniak F, Jeanmougin F, Higgins DG: The CLUSTAL_X windows interface: flexible strategies for multiple sequencealignment aided by quality analysis tools. Nucleic Acids Res 1997 25:4876-4882.

28. Hall TA: BioEdit: a user-friendly biological sequence alignment editorand analysis program for Windows 95/98/NT. Nucleic Acids Symp Ser 1999, 41:95-98.

29. Rozas J, Sanchez-DelBarrie JC, Messeguer X, Rozas R: DNASP: DNA polymorphism analyses by the coalescent and other methods. Bioinformatics 2003, 19:2496-2497.

30. Pons $\mathrm{O}$, Petit RJ: Measuring and testing genetic differentiation with ordered versus unordered alleles. Genetics 1996, 144:1237-1245.

31. Nei M: Molecular Population Genetics and Evolution. Amsterdam: North-Holland Publishing Company; 1975.

32. Excoffier L, Laval G, Schneider S: Arlequin version 3.0: an integrated software package for population genetics data analysis. Evol Bioinform Online 2007, 1:47-50.

33. Peakall R, Smouse PE: GenAlEx 6.5: genetic analysis in excel, population genetic software for teaching and research-an update. Bioinformatics 2012, 19:2537-2539

34. Tamura K, Peterson D, Peterson N, Stecher G, Nei M, Kumar S: MEGA5: molecular evolutionary genetics analysis using maximum likelihood, evolutionary distance, and maximum parsimony methods. Mol Biol Evol 2011, 10:2731-2739.

35. Jin L: Studies on molecular phylogeography and genetic diversity of genus Calligonum L. Beijing: University of the Chinese Academy of Sciences; 2007. Graduate thesis.

36. Lu JY, Yang XM, Ma RJ: Genetic diversity of clonal plant Polygonumviviparum based RAPD in eastern Qinghai-Tibet Plateau of China. Northwest Norm Univ 2008, 44:66-72.

37. Xiao LQ, Ge XJ, Gong X, Hao G, Zheng SX: ISSR variation in the endemic and endangered plant Cycas guizhouensis (Cycadaceae). Ann Bot 2004, 94:133-138.

38. Li FG, Xia NH: Population structure and genetic diversity of an endangered species, Glyptostrobus pensilis (Cupressaceae). Bot Bull Acad $\sin 2005,46: 155-162$.

39. Amos W, Harwood J: Factors affecting levels of genetic diversity in natural populations. Philos T Roy Soc B 1998, 1366:177-186.

40. Joshi SP, Gupta VS, Aggarwal RK, Ranjekar PK, Brar DS: Genetic diversity and phylogenetic relationship as revealed by inter simple sequence repeat (ISSR) polymorphism in the genus Oryza. Theor Appl Genet 2000, 100:1311-1320.

41. Hamrick JL, Godt MJW: Eeffects of life history traits on genetic diversity in plant species. Phil Trans R Sco Lond B 1996, 351:1291-1298.
42. Zheng HJ, Wang $H$, Yang $H$, Wu JH, Shi B, Cai R, Xu YB, Wu AZ, Luo LJ: Genetic diversity and molecular evolution of Chinese waxy maize germplasm. Plos one 2013, 8:e66606.

43. Hamrick JL, Godt MJW: Conservation Genetics: Case Histories from Nature. New York: Oxford University Press; 1996.

44. Kimura M: The Neutral Theory of Molecular Evolution. Oxford: Cambridge University Press; 1984.

45. Barrett SCH, Kohn JR: Genetics and Conservation of Rare Plants. New York: Oxford University Press; 1991.

doi:10.1186/1749-8546-9-26

Cite this article as: Zhang et al:: Genetic diversity and population structure of Rheum tanguticum (Dahuang) in China. Chinese Medicine 2014 9:26.

\section{Submit your next manuscript to BioMed Central and take full advantage of:}

- Convenient online submission

- Thorough peer review

- No space constraints or color figure charges

- Immediate publication on acceptance

- Inclusion in PubMed, CAS, Scopus and Google Scholar

- Research which is freely available for redistribution 